\title{
Unravelling Business Negotiations Using Practitioner Data
}

\author{
Ray Fells \\ University of Western Australia, Perth, Australia. \\ Helen Rogers \\ Nuremberg Institute of Technology, Germany \\ Peter Prowse \\ Bradford University School of Management, UK. \\ and \\ Ursula Ott \\ Loughborough University, UK.
}

Corresponding author

\section{Prof. Helen Rogers}

Business Faculty

Nuremberg Institute of Technology

Bahnhofstrasse 87, Nuremberg

90402 Germany

e: Helen.rogers@th-nuernberg.de

Tel: 004991158802833 


\begin{abstract}
Although negotiations are a core business activity there is a lack of information about what actually occurs during a business negotiation. This study addresses this issue though an international survey of managers focusing on actual negotiations. The 294 respondents reported on what actions they took as they sought to achieve an agreement, including how information was exchanged, how they looked for new solutions and managed concession making. The analysis suggests a pragmatic approach to negotiation, whereby information is not withheld, but neither is it freely given. Solutions emerge from discussion of priorities and commonalities, rather than through more formal creative processes. The underlying script of negotiation appears to draw more on competitive than overtly collaborative tactics, suggesting that business negotiators are cautious co-operators. Further research avenues include investigating the pressures and context that impact upon negotiators' decision making and closer examination of interactions between negotiation tasks en-route to an agreement.
\end{abstract}

Keywords: International business negotiations, negotiation processes and tasks, outcome satisfaction 


\section{Unravelling Business Negotiations Using Practitioner Data}

"I negotiated a two year service level agreement with a monopoly supplier. We negotiated over a six month period and met multiple times using face to face and conference calls. We moved from sorting the scope to more detailed discussions to running test phases to finally signing." (Procurement Manager)

"I negotiated a purchase order with a supplier. We met their representatives twice and about 10 times via tele-conversation. We communicated the requirements and specifications by tele-conversation. The first meeting sorted out the details of the deal and quality concerns; the second meeting sorted out the terms. Following the multiple tele-conferences, we were able to agree on final terms that were acceptable to us." (Procurement Supervisor)

Very little in business seems to happen without negotiation. Procurement contracts have to be secured; finance has to be raised; production schedules have to be finalized; there needs to be a sales contract with any number of clauses covering price, delivery, quality, risk mitigation. Managers might find themselves negotiating with government officials, environmental groups, indigenous communities or - if something goes wrong - with lawyers and regulators. A deeper understanding of how negotiators negotiate and how the negotiation process 'works' in the business context will contribute to more effective business practices. To this end, this paper provides insights from a survey of nearly 300 negotiation practitioners. The survey findings revealed that the tactics they each used in one of their business negotiations and offer insights into how the components of the negotiation process work together to produce a satisfactory outcome. Drawing upon practitioner data to complement findings from other research settings strengthens the links between research and practice as well as suggesting further avenues of exploration (Buelens, Van de Woestyne, Mestdagh \& Boukenooghe, 2008; Carnevale \& Dreu, 2005).

Knowledge of negotiation has been gained from contexts as diverse as international relations and the workplace. From the early manuals on diplomacy, the field of international relations has provided insights into how issues are resolved with researchers developing a range of analytical tools, from game theory through to content analysis (Axelrod, 1990; Deutsch, 1973; Druckman, 2005; Raiffa, 1982; Schelling, 1960; Sebenius, 2009), much of which can be applied to business negotiation. For example, drawing on their insights into international negotiations, Zartman and Berman (1983) suggested that negotiators should first 
develop a framework for a settlement and then work together to complete the details. This approach is recognizable in the business context where a typical sequence for a business acquisition negotiation would be for the parties to establish the key parameters of a settlement in a 'memorandum of understanding', and then within that framework 'fill in' the detail.

The work of Douglas (1957), Stevens (1963), and Walton and McKersie (1965) established a field of research into negotiation and mediation from a labor relations perspective, which also provided insights into how business negotiations in general might be conducted (not merely negotiations with unions). Both Douglas (1957) and Stevens (1963) identified phases in the negotiation process that the notion of phases underpinning much research into tactical behavior by negotiators. Walton and McKersie's(1965) behavioral theory -, and in particular their analysis of distributive and integrative bargaining, laid the foundations for much subsequent research across all fields of negotiation. Negotiation texts, such as Hames (2012), Lewicki, Minton and Saunders (2010), and Thompson (2012), have used the Walton and McKersie conceptualization to describe the core strategies of negotiation, irrespective of the context. Lax and Sebenius (1986), writing specifically for the manager, parallel Walton and McKersie's (1965, pp.161-169) mixed strategy approach with their own notions of creating more value and then claiming a share of it. Furthermore, Lempereur and Colson (2010) envisaged a similar strategic sequence for a negotiation to be successful.

Managers (or indeed any negotiators for that matter) seeking to improve their negotiations should pay attention to the interest-based approach, first popularized by Fisher and Ury (1981), that has formed the core of much negotiation research and practice (e.g., Thompson \& Leonardelli, 2004). Negotiation scholars writing specifically for the business context, such as Lax and Sebenius (1986), Movius and Susskind (2009), and Watkins (2002), have built upon this interest-based approach, although Wheeler (2013) has suggested that business negotiations are more complex in that negotiators need a sense of direction, but must be able to manage uncertainty and indeed chaos. Similarly, Watkins (2006) believed that leaders need to pay attention to shaping the game both at the table and away from it when they are negotiating. Such considerations suggest that the dynamics of the negotiation process as it unfolds in business contexts will encapsulate the practical insights gained from research under controlled conditions but may well involve other elements due to the complexity of the context. 
Accounts of major business negotiations attest to their complexity. For example, Weiss (2011) described merger negotiations between two car companies that progressed through five different phases over a period of a year, with the companies also having to manage a complex web of stakeholders and competitors. The need to gain entry and establish an appropriately structured business model adds complexity and competitiveness when the business negotiations are international (Ghauri \& Usunier, 2003; Hendon, Hendon, \& Herbig, 1996; Kumar \& Worm, 2004; Schuster \& Copeland, 1996).

Most business negotiations are of a smaller scale, as exemplified by the two brief quotes at the start of this article taken from managers who took part in the research, and this may constrain the approach that the negotiators take. Ramsey (2004) found resistance to cooperative negotiation approaches amongst practicing buyers. The competitive context of many business negotiations is reflected by another manager (survey respondent) in his description of a negotiation:

I was involved in a negotiation relating to the supply of printing products. We had two negotiation-related meetings about storage, delivery, logistics and service support. The price factor was wagered in a third meeting because of our concern of threats from a (competitor) company. (Procurement manager)

The negotiators from two companies that had undertaken to cooperate over the share of infrastructure took over six months to reach an agreement (Fells, 2013). When researchers gain direct access to 'real life negotiations', which seems to occur more often with management-union than with business negotiations, they find that the use of contentious tactics and how arguments are shaped are an integral part of the interactive process (Douglas, 1962; Goering, 1997; Putnam \& Wilson, 1989; Fells, 2000). Further exploration of practitioners' experiences would provide insights into the competitiveness in their negotiations and, in consequence, the scope - and the need - for them to adopt more collaborative value-creating approaches that are typically recommended in the negotiation literature.

\section{Negotiation as a Process of Tasks to be Worked Through}

At its most basic, 'negotiation is a process of combining conflicting positions into a common position' (Zartman, 1988, p. 32). Much of the research into negotiation is an investigation into just how negotiators do this. That negotiation is a 'process' that implies a sequence of activities through which the parties get from their conflicting positions to a 
common point (which may, incidentally, be that they both walk away with no agreement). Rubin and Brown (1975) described this sequence as "the presentation of demands or proposals by one party, evaluation of these by the other, followed by concessions and counterproposals" (p. 18). Negotiation involves a mix of both collaborative and more competitive or persuasive activities, which may be identifiable as phases or stages in the negotiation. These phases of cooperation and competitiveness can occur because the negotiators develop a strategy to create value before claiming their share of it (Lax \& Sebenius, 1986; Walton \& McKersie, 1965). The sequential nature of negotiation can also emerge where the parties follow the inherent logic of decision making: understand the difficulty, identify options, decide upon one of them, as exemplified by the phase models of negotiation (Douglas, 1957; Fisher, Ury \& Patton, 1991; Holmes, 1992; Olekalns, Brett \& Weingart, 2003). Within these overall patterns, the language of negotiators suggests both competitiveness and cooperativeness appear to feed off each other as the parties search for a way forward (Putnam, 2010; Putnam \& Fuller, 2014). Negotiators have to make sense of the unfolding dynamic and improvise around their negotiation script if they are to combine conflicting positions into a common position (Brett, 2014; Fells, 2012; McGinn \& Keros, 2002; Wheeler, 2013).

Fells (2012) described this complex process as "negotiation is a process through which two parties with differences that they need to resolve try to reach agreement through exploring for options and exchanging offers' (p. 3). Even this does not include the important task of preparation for negotiation, but it does indicate the two main ways that a common position may emerge - through the creative development of options and/or through the more competitive trading of offers. To reach an agreement, negotiators would therefore expect to undertake four key tasks: preparation, information exchange, solution seeking, and concession management (Figure 1). As indicated above, negotiations can be described as going through phases or stages. Regarding a negotiation as a series of tasks - things that ought to be done if an agreement is to be achieved - adds a greater sense of purpose to the process and so is the perspective taken in this paper.

Figure 1 A model for business negotiations (based on Fells, 2012) ABOUT HERE 
Not all negotiations go smoothly, so deadlocks are possible. A further dimension to negotiation is the parties' appreciation of their power position which they acquire through their preparation and through learning more during the negotiation itself. The outcome of a negotiation has two aspects: the settlement (which can include no agreement) and the process aftermath. These various elements of negotiation - the tasks, appreciation of power, possible deadlocks and the parties' satisfaction with the outcome provided the structure for data collection through the questionnaire. For the purposes of this paper, we focus on the direct path to a negotiated outcome, the four key tasks of Table 1. The effects of deadlocks and power, while both interesting factors, add considerable complexity to the model of a negotiated outcome and were considered out of scope for this initial study.

A review of the research literature on negotiation activities within each task again prompts the question: to what extent do negotiation practitioners employ these tasks as they seek to achieve an agreement? That a negotiation involves a series of tasks gives rise to a second question: how do these tasks fit together to make a negotiation 'work'? The review suggests a number of hypotheses and these are shown in Figure 2.

Figure 2 Task model of negotiation with task-related hypotheses

ABOUT HERE

Preparation is an important but complex task that impacts upon one's effectiveness in the ensuing negotiation (Rackman \& Carlisle, 1978; Roloff \& Jordan, 1991). There are many frameworks to guide negotiators in this task (e.g. Fisher \& Ertel, 1995; Peterson \& Lucas, 2011; Lewicki, et al., 2010, Watkins, 2002), the primary objective being to better one's understanding of the context within which the negotiations are occurring, the interests of the both parties and what they hope to achieve out of the negotiations.

The logic of the task oriented approach suggests that the more information a negotiator has gained through preparation, the more likely he/she is to share and also gain information rather than just place a position on the table (Fells, 2012; Fisher \& Ertel, 1995; Ghauri \& Usunier, 2003). Similarly, better preparation will open up possible solutions, again leading to more solution oriented rather than positional activity in the negotiation (Fisher et al., 1991; Rackman \& Carlisle, 1978; Roloff \& Jordan, 1991; Salacuse, 2003). Negotiators who are prepared and so have opened up the possibilities within the negotiation are then less likely to have to engage in trade-offs or pressure tactics to find an agreement because they are more 
likely to have found a solution that is mutually beneficial (Fells, 2012; Ghauri \& Usunier, 2003; Rogers, Hossinger, Perks \& Ghauri, 2010). We would anticipate a cumulative positive effect such that more preparation leads to more information exchange, which in turn leads to more looking for solutions, thus making concession management less necessary. The three hypotheses can be expressed as follows:

Hypothesis $1\left(H_{1}\right)$. It is predicted that greater preparation prior to a negotiation will lead to more information exchange.

Hypothesis $2\left(\mathrm{H}_{2}\right)$. It is predicted that greater preparation prior to a negotiation will lead to more solution seeking.

Hypothesis $3\left(\mathrm{H}_{3}\right)$. It is predicted that greater preparation prior to a negotiation will lead less concession management.

Once the negotiations have started, information exchange is at the heart of process (De Dreu, Beersma, Stroebe \& Euwema, 2006; Thompson, 1991). The task of sharing information and gaining insights from the other party involves questioning, responding and listening that enables the parties to increase their understanding of each other's situation and particularly their priorities. However, if the information is ambiguous then it can slow down a settlement (Loewenstein \& Moore, 2004).

Even without much preparation, if negotiators exchange information at the negotiating table, then they will find it easier to move into solution seeking (Butler, 1999; Graham, 1986; Pruitt, 1983; Thompson, 1991; Weingart, Thompson, Bazerman \& Carroll, 1990) and have less need to engage in concession management (Fisher et al., 1991; Salacuse, 2003; Weingart et al., 1990.). We therefore propose:

Hypothesis $4\left(\mathrm{H}_{4}\right)$. More information exchange leads to the negotiation participants being more likely to look for solutions (i.e., solution seeking).

Hypothesis $5\left(\mathrm{H}_{5}\right)$. More information exchange leads to less concession management.

The task of solution seeking involves looking for possible ways to resolve the issues other than using any positions that may have already been put forward; it is related to creativity (but doesn't imply the negotiators did actually find a creative solution). Bazerman and Neale (1992) suggested a number of ways (in addition to exchanging information) to find new value adding solutions including regarding differences as opportunities and continuing to search for a better solution. New solutions can emerge from open brainstorming (Fisher et al., 1991; Ury, 1991); and spontaneously ('ah ha' moments - see Putnam, 2010). The more 
negotiators have engaged in the task of seeking solutions the less likely are they to have to engage in making concessions to reach an agreement (Weingart et al., 1990) which leads to a further hypothesis:

Hypothesis $6\left(H_{6}\right)$. It is predicted that more solution seeking will lead to less concession management

The final task in a negotiation is that of concession management, securing or perhaps giving concessions to bring tentative suggestions or divergent positions into a point of agreement. Negotiators can do this through continually restating one's case (e.g., positional arguing, Olekalns \& Smith, 2003; argumentation, Putnam \& Wilson, 1989), making trades (i.e., logrolling); splitting the difference; using external criteria (Fisher et al., 1991); making a unilateral concession to encourage the reciprocal response (Kwon \& Weingart, 2004) and making personal appeals or threats (Rubin, Pruitt, \& Kim, 1994; Sineaceur \& Neale, 2005).

The various hypotheses posed above all work towards the conclusion that concession management is what occurs in default of the other three tasks. The general proposition is that there is a positive sequential effect between preparation, information exchange and looking for solutions, while a failure to engage in these tasks will then require more concession management to achieve an agreement. Together the six hypotheses deal with whether one task in the negotiation process is likely to lead to more or less of another en-route to an agreement.

Negotiation is a purposeful activity with each party seeking to achieve an outcome at least as good as might be obtained elsewhere (Fisher et al., 1991; Rubin \& Brown, 1975). A further question then arises - to what extent do the four tasks, either separately or in combination, contribute to a satisfactory outcome to the negotiation? As with the individual negotiation activities, the findings from experimental settings provide good indications of the factors that lead to successful outcomes but practitioner settings can provide additional insights (Fells, 2013; Halpert et al., 2010) into how the negotiation process works.

When negotiators prepare and then engage in information exchange they can anticipate more satisfactory outcomes (Fisher \& Ury, 1981; Ghauri \& Usunier, 2003; Salacuse, 2003). In a similar way, the more collaborative solution seeking approach in negotiation will lead to more satisfactory outcomes (Halpert et al., 2010; Weingart \& Olekalns, 2004) while there is less satisfaction emerging when negotiators have had to engage in concession management activities (De Dreu, Weingart \& Kwon, 2000; De Dreu, Giebels, \& Van de Vliert, 1998; Kwon \& Weingart, 2004). Four hypotheses can be proposed about what actions by negotiators would lead to greater satisfaction with the outcome: 
Hypothesis $7\left(\mathrm{H}_{7}\right)$ : It is predicted that more preparation will lead to greater satisfaction.

Hypothesis $8\left(\mathrm{H}_{8}\right)$ : It is predicted that more information exchange will lead to greater satisfaction.

Hypothesis $9\left(\mathrm{H}_{9}\right)$ : It is predicted that more solution seeking will lead to greater satisfaction.

Hypothesis $10\left(\mathrm{H}_{10}\right)$ : It is predicted that more concession management will lead to lower satisfaction.

\section{Method}

As indicated above, access to negotiations in live settings is far less common but when it is granted researchers are able to closely analyze what negotiators do through what they say and how they manage the words they use both at the table and away from it (Maynard, 2010; Putnam, 2005; Putnam \& Fuller, 2014). Careful analysis of interactions in simulated negotiations also provides insight into how negotiators manage their strategies and tactical moves (Weingart \& Olekalns, 2004), but ethnographic studies are rich in capturing the way words take on meaning that is specific to the context, such as, the use of the labels 'language' and 'money' in a labor contract negotiation (Putnam, 2003). In a business negotiation, the equivalent terms might be 'scope' and 'financials'.

Surveys are reported on far less often than experimental results though the subjects do tend to be managers rather than students (Agndel, 2007). The research examined in this article uses a survey approach as the best practical method to obtain data on negotiations occurring in a business context. The intent was to access individuals who were directly involved in negotiations in a work context. They were asked to focus on a specific negotiation that they had been involved in, and to record what strategies and tactics were used. Rather than responding with what they typically do in a negotiation (or would prefer to do), the survey questions sought data on what they and the other party actually did. In this way, each questionnaire provides a snapshot of the whole process from initial differences to agreement or in some cases to the parties ending the negotiation without reaching an agreed settlement.

Surveys are not without their challenges. Questionnaires are dependent on the respondent's powers to recall, incurring the risk of self-serving bias in the recollections, the inability to triangulate or obtain parallel data from the party on the other side of the negotiating table (Field, 2005; Ghauri \& Grønhaug, 2010). Generalizability of findings on a relatively small sample is also an issue (Miles \& Huberman, 1994). Steps were taken to 
prevent the trap of a convenient sample through using multiple sources across the world (this is explained in more detail in the data collection section).

The conclusions are tentative owing to the sample size and the inherent limitations of research that relies on self-reported survey data. As such, one must bear in mind that participants may not have responded accurately, nor do their responses indicate the effectiveness of their actions. Despite limitations, the contribution of this approach lies in the way that it provides data on real business negotiations that is informative in its own right but which also provokes further avenues for research, some of which are identified later in the paper.

\section{Questionnaire Development}

In the survey, participants were asked the extent to which they considered a range of factors drawn from the framework developed by Fells (2012), which were the importance of the issue, time pressure and alternatives, the other's likely strategy, and the desired outcome from the other party's perspective.

Information related statements can be precisely categorized for research purposes, for example, positions or facts (distributive information) or priorities, needs and interests (integrative information) (Olekalns, Brett \& Weingart, 2003). In seeking to uncover the working dynamics of the negotiation process, the questionnaire sought to obtain practitioner responses to a more task-related question; 'how did you gain insight into what the other party really wanted and were prepared to agree to?' The response set (Table 1) focused more on how information was exchanged than its specific content. It provides, for example, for the realistic possibility that a negotiator, through their prior preparation, already had a good insight into what the other party wanted. This source of 'information exchange' would not be observed though analysis of statement categories, except perhaps indirectly though identifying questions asked by the negotiator that had the purpose of confirming their prior understanding of the other party's interests and positions.

Table 1 Survey questions on information exchange

ABOUT HERE 
The same approach was taken for the second negotiation task, that of finding solutions. The question asked was, 'to what extent were any of the following used to develop new suggestions or proposals to resolve the differences between the parties?' The questionnaire gave a choice of seven possible responses, solution-seeking activities derived from the literature ranging from specific times of brainstorming to continuing to search even though a satisfactory solution had been found. One response option provided for when suggestions were developed away from the table, not normally an option in most experimental settings. Negotiators were also asked how they persuaded the other party to agree. The response options identified from the research literature included restating one's case, expecting the other to agree, trading off less for more important items, splitting the difference, and making personal appeals or threats.

\section{Data Collection}

The survey instrument (questionnaire) was generated and administered electronically using an Internet-mediated survey software program (i.e., Survey Monkey) and consisted of a combination of closed-answer questions on a Likert scale, as well as open-ended items. The questionnaire was structured around the elements of negotiation shown in Figure 1. An introductory section covered issues such as role, country, years of experience, type of negotiation, and cultural background of the participant. The questionnaire was developed in a multistep process, adapting questions from previous studies including a pre-test (pilot) which served to examine the reliability, clarity and validity of the questionnaire items (Saunders et al., 2007: 387). The pilot version of the questionnaire was completed by 20 managers (each with at least 5 years negotiating experience) in Perth, Western Australia and in Manila, Philippines. Drawing on their feedback the questionnaire was simplified and clarified. An open-ended summary question was retained at the start of the questionnaire to help the respondent focus on a particular negotiation, rather than give generalized responses. The questions followed the anticipated sequence of a negotiation: preparation; gaining insights; developing new suggestions and methods of persuasion. After a question about the type of agreement reached (which included a 'no agreement' option) respondents were asked their level of satisfaction with the outcome and with the process of negotiation. As indicated above, the response options were couched in general language.

Participants, who completed the final survey, were drawn primarily from graduate management programs and alumni lists from business schools. These included business schools in Australia, Denmark, The Emirates, Germany, Hong Kong, Singapore, the United Kingdom and the United States. Additionally, a number of professional organizations in 
general management, human resources and supply chain management were approached and they informed their memberships of the survey, so encouraging participation $(\mathrm{Zu}, 2012)$. Responses were gained by contacting professional business organizations/networks to ensure that the emphasis was on active managers.

The questionnaire was hosted on Survey Monkey for a period of 12 months until mid 2012. Using an online facility enabled a broad field of respondents to take part in the survey. However, invitations to participate in online surveys do not yield good response rates and, as anticipated, the majority of respondents were in response to invitations to participate by the authors or colleagues. Owing to the fact that the 'invitation to participate' link was forwarded by social media, it is not possible to determine the response rate. Previous research suggests that response rates for surveys sent through email are relatively low as compared to traditional mail surveys (Michaelidou \& Dibb, 2006; Saunders et al., 2007). Although it is difficult to prove, it is fair to assume the two main reasons for non-responses were not actually receiving the questionnaire (out of date contact details) and the intention not to respond (Baruch and Holton, 2008). Additionally, as is the case with many studies of this nature, the issue of response bias also plays a role in the responses received. In all cases completion of the survey was on a voluntary basis. By the deadline date, the number of utilizable surveys was 294. They were drawn from a range of industries and involved negotiations that occurred across international borders. The role of the respondent at the time of their negotiation included owner/CEO (6\%), general managers (18\%), a buyer's role (12\%), sales and human resources (both 11\%). 15\% of respondents had a technical expertise role such as a lawyer or information systems manager. In terms of the type of negotiation under consideration, the two dominant types were procurement and sales negotiations (28\% and $23 \%$ respectively) followed by commercial negotiations $(14 \%)$.

\section{Results}

\section{What Do Negotiators Do?}

Negotiators need to get to understand the other party's position, interests and general situation as well as getting the other party to do the same. Accepting that some had worked out the other side's situation through their preparation, the dominant methods appear to be through information sharing (i.e., offering insights) and through focusing on common ground. The need to offer insights (e.g., to encourage the other party to do likewise) suggests a careful exchange of information, rather than a fully open one. Interestingly negotiators did not rely on gaining insights through focusing on their differences (Figure 3). 
The negotiators used a range of techniques to generate new solutions but with no clear preference (Figure 3), perhaps indicating that they are being opportunistic in how they sought new ways to resolve the issues. However, they did not appear to focus on their differences, nor continue to search for better solutions. This might suggest that their collaborative efforts were directed more to accommodating each other across some middle ground rather than pushing the limits in pursuit of more joint value. A significant proportion indicated that solutions were found unilaterally rather than in joint session. It is not clear from the responses which of the solution seeking activities most generated possible solutions that then became the actual solution.

Negotiations also involve persuasion as possible solutions have to be agreed upon - the strategy of creating value is followed by a need to claim value. Restating one's case and trading off less important items (the latter arising out of the discussion of priorities, above) were the most relied upon. The absence of threats suggests that the end-game of the negotiations was not overtly competitive.

Figure 3 What do negotiators do? Information exchange and seeking solutions ABOUT HERE

\section{How Do The Tasks Fit Together To Make a Negotiation Work?}

Three hypotheses (i.e., $\mathrm{H}_{1}, \mathrm{H}_{2}$, and $\mathrm{H}_{4}$ ) suggest that there are positive links between three elements in negotiation - preparation, information exchange and solution seeking. Using regression analysis, we first examined the effect of one element on another, the relationship between one and another, as well as the proportion of variances in the hypothesized outcomes accounted for the predictor (analysis of the effect on satisfaction appears later).

The three hypotheses are that more preparation leads to a higher level of information exchange $\left(\mathrm{H}_{1}\right)$ and has a positive effect on the extent of solution seeking $\left(\mathrm{H}_{2}\right)$, and that more information exchange has a positive effect on the extent of solution seeking $\left(\mathrm{H}_{4}\right)$. These three hypotheses were supported. Preparation significantly predicted information exchange in the positive direction, $\beta=.30, t(279)=5.20, p<.001$. Preparation also explained a significant proportion of variance in information exchange, $R^{2}=.09, F(1,279)=27.03, p<.001$.

Preparation significantly predicted solution seeking in the positive direction, $\beta=.32, t(279)=$ $5.65, p<.001$. Preparation also explained a significant proportion of variance in solution seeking, $R^{2}=.10, F(1,279)=31.94, p<.001$. Additionally, information exchange 
significantly predicted solution seeking in the positive direction, $\beta=.46, t(279)=8.56, p<$ .001. Information exchange also explained a significant proportion of variance in solution seeking, $R^{2}=.21, F(1,279)=73.33, p<.001$.

Three further hypotheses (i.e., $\mathrm{H}_{3}, \mathrm{H}_{5}$, and $\mathrm{H}_{6}$ ) suggested negative relationships between some negotiation tasks, namely that if negotiators performed the tasks of preparation, information exchange and looking for solutions well there would be less need for concessions. Expressed another way, if preparation and/or the exchange of information was inadequate or looking for solutions proved unsuccessful, then all the negotiators would be left with is the task of making and managing concessions if they are going to achieve an agreement. Again, simple regression analysis was used to test the hypothesized relationships

The results are somewhat contrary to expectations. There are positive, not negative relationships between preparation, information exchange, solution seeking and concession management. Preparation significantly predicted concession management in the positive direction, $\beta=.23, t(279)=3.91, p<.001$. Preparation also explained a significant proportion of variance in concession management, $R^{2}=.05, F(1,279)=15.30, p<.001$. Information exchange significantly predicted concession management in the positive direction, $\beta=.21, t(279)=3.61, p<.001$. Information exchange also explained a significant proportion of variance in concession management, $R^{2}=.05, F(1,279)=13.05, p<.001$. Additionally, information exchange significantly predicted solution seeking in the positive direction, $\beta=.38, t(279)=6.96, p<.001$. To round this off, information exchange also explained a significant proportion of variance in solution seeking, $R^{2}=.15, F(1,279)=48.38, p<.001$.

\section{What Led to Satisfactory Outcomes?}

Half of the negotiations (50\%) resulted in a single formal agreement, with a further $25 \%$ producing a series of agreements. Only $8 \%$ of the negotiations failed to reach agreement. However we should note that a similar percentage $(7 \%)$ of respondents were also either very or extremely dissatisfied with the settlement, which may suggest that they should not have agreed to it. Approximately one third (34\%) of respondents expressed only moderate satisfaction with the process, and similarly with regard to the settlement. Notwithstanding the proportion of respondents $(50 \%)$ who had greater levels of satisfaction arising from their negotiations, these significant 'moderately satisfied' categories suggests that there is room for improvement in the negotiations.

The model suggested two dimensions as to whether a negotiator is satisfied with the outcome of a negotiation, one relating to the settlement itself and the other relating to the 
process. There was a significant positive correlation between satisfaction with the settlement and satisfaction with the process with moderate to strong strength, $r=.64, p<.001$.

Nevertheless, as will be shown below, different aspects of the negotiation contributed to the levels of settlement and process satisfaction.

The hypotheses relating the tasks to satisfaction were that more preparation will lead to greater satisfaction $\left(\mathrm{H}_{7}\right)$, as would both more information exchange $\left(\mathrm{H}_{8}\right)$ and more solution seeking (H9). However, having to engage in more concession management, reflective of a more competitive end-game when compared to the potentially more cooperative solution seeking, will result to lower satisfaction $\left(\mathrm{H}_{10}\right)$. Regression analysis on the relationships between each individual negotiation task and satisfaction with the settlement (SS) shows the following: Preparation significantly predicted SS, $\beta=.15, t(280)=2.52, p=.012$. Preparation also significantly explained a significant proportion of variance in SS scores, $R^{2}=.02, F(1$, $279)=6.33, p=.012$, supporting H7. Information exchange significantly predicted SS, $\beta=.13$, $t(280)=2.23, p=.026$. Information exchange also explained a significant proportion of variance in SS scores, $R^{2}=.02, F(1,279)=4.98, p=.026$, supporting H8. Solution seeking significantly predicted SS, $\beta=.12, t(280)=1.99, p=.048$. Solution seeming also explained a significant proportion of variance in SO scores, $R^{2}=.01, F(1,279)=3.95, p=.048$, supporting H9. In addition, concession management did not significantly predict SS.

However, an alternative understanding of how negotiations 'work' is that negotiation is 'messy', that the tasks are not compartmentalized and so their effect is not direct or linear. Instead each task element contributes to an overall understanding of what is possible in the negotiation. To explore this we tested for multiple regressions, with preparation, information exchange, solution seeking entered as predictors and satisfaction with the settlement (SS) and with the process (SP) as the outcome. The standard multiple regression analysis revealed that the proportion of variance in SS accounted for by preparation $(\beta=.13, p=.045)$, information exchange $(\beta=.08, n s)$, solution seeking $(\beta=.10, n s)$, and concession management $(\beta=-.15, p=$ .022 ) was $5 \%$, which was significant, $\mathrm{R}_{\mathrm{ch}}{ }^{2}=.05, F_{\mathrm{ch}}(4,276)=3.69, p=.006$. The unique contributions to the variance in SS by preparation was $1.4 \%\left(s r^{2}=.014\right)$, by information exchange was $0.5 \%\left(s r^{2}=.005\right)$, by solution seeking was $0.6 \%\left(s r^{2}=.006\right)$, and by concession management was $1.8 \%\left(s r^{2}=.018\right)$. Hence, the shared variance was $0.7 \%$. This suggests that the 'core' elements of a negotiation, the elements that matter in relation to satisfaction with the settlement, are preparation and concession management.

The standard multiple regression analysis revealed that the proportion of variance in SP accounted for by preparation $(\beta=.16, p=.010)$, information exchange $(\beta=.24, p<.001)$, 
solution seeking $(\beta=.01, n s)$, and concession management $(\beta=-.09, n s)$ was $10 \%$, which was significant, $\mathrm{R}_{\mathrm{ch}}{ }^{2}=.10, F_{c h}(4,276)=7.77, p<.001$. The unique contributions to the variance in SP by preparation was $2.2 \%\left(s r^{2}=.022\right)$, and by information exchange was $4.3 \%\left(s r^{2}=.043\right)$, by solution seeking was $0.01 \%\left(s r^{2}=.0001\right)$, and by concession management was $0.7 \%\left(s r^{2}=\right.$ $.007)$. Hence, the shared variance was $2.8 \%$.

\section{Discussion}

The findings of this research show that business negotiators are pragmatic and only cautiously cooperative in their approach to negotiations. They use a range of actions to achieve progress towards an outcome, which indicates there is no one clear way that negotiators approach the task of reaching an agreement. At a general level, this is unsurprising and is indeed in line with previous negotiations research. While it could be argued that negotiators would follow a better path to an agreement if only they were properly trained, our results reflect the interactive nature of negotiations. By this we mean that the tactics/actions by one side are reacted to by the other and that there is interdependence of competitiveness and cooperation (as opposed to negotiation clearly being either competitive, cooperative or 'principled'). Furthermore, the process is dynamic, necessitating a degree of pragmatism at the negotiation table.

Activities such as brainstorming or searching for still better solutions reflect a fully rational decision making approach to negotiation. However negotiators prefer a more cautious common ground approach. They are not too open to giving information and they look to generating solutions in private, rather than in joint discussion. These activities reflect upon negotiation as being a competitive undertaking rather than a fully collaborative one. Negotiation activities such as these also reflect a task-oriented approach, whereby the purpose is to reach an acceptable - rather than ideal - agreement.

This pragmatic, task oriented and somewhat competitive approach is perhaps a consequence of the context within which business negotiations occur and in this regard, the information about practitioners' negotiations adds to our understanding of negotiation dynamics. Although some contextual factors - such as time pressure - can be abstracted and examined in experimental settings (e.g., Stuhlmacher \& Champagne, 2000) it is a challenge to recreate the complexity of pressures that impact upon a negotiator's motivations which, it would seem, push the negotiators towards the more competitive end of the negotiation behavior spectrum. Business negotiations often take place in situations where time is important and where priorities of revenue, cost control or risk minimization form a generally competitive environment within which the negotiations take place. Organizational cultures 
such as a 'can do' mentality can be supportive of achievement but at the same time can put pressure on negotiators to be deal makers, to focus on completing the current deal so as to be able to move on to the next. Clearly it is impossible to divorce a negotiation from the context that gives rise to it. However, the scheduling of any business activity that is going to involve negotiation should factor in an appropriate timeframe to avoid the situation of the negotiations operating in a 'crisis management atmosphere'.

The survey responses reveal the complex and competitive nature of many business negotiations. One implication for negotiators is that too idealistic an approach - a script that envisages both parties working though openly sharing information and freely generating solutions - is not likely to be reciprocated. Negotiators need to be pragmatic in their approach and recognize that it will take two or more attempts at employing some of the more open, constructive activities such as sharing some information to encourage reciprocity/build trust or openly discussing the other party's proposals before the other party begins to open up. At the same time, any seemingly competitive actions by the other party should be met with only a measured response.

An example might be that when one negotiator offers some sensitive information but the other does not. Rather than focus on this non-reciprocal exchange (e.g., 'we've provided you with information, but you are not telling us anything; do you really want an agreement here?'), the negotiator should instead revert to restating her main points and concerns (also see Brett, Shapiro \& Lyte, 1998). Only later should the 'missing' reciprocation be sought (i.e., 'we need more information if progress is going to be made'). This highlights the need for negotiation skill development to recognize the interactive nature of the process. Not only do negotiators need to develop skills in what they should be doing, they also need to develop the skill of correctly interpreting the other negotiator's behavior and then managing one's own reaction to it.

The earlier comments about the context of business negotiations suggest additional research may be required to better understanding the pressures experienced by business negotiators and how these contextual pressures influence what the negotiators settle for, or even set out to achieve. Setting strong goals leads to success in negotiation (Halpert et al., 2010) but an exploration of what business negotiators set out to achieve may reveal that they set satisficing rather than maximizing goals. The conflicting business pressures on a negotiator may stifle the push for the 'sweet spot' (Susskind, 2014) that is close to the other party's walk away point. 
We premised that the process of reaching agreement through negotiation involves four main tasks: preparation, information exchange, solution seeking and concession management. All four tasks are found to be mutually supportive, as they all contribute towards achieving the outcome; it does not seem that a sequence of just preparation, information exchange and solution seeking is sufficient to achieve agreement. What is somewhat surprising is that our results indicate that information exchange is not as important as might be expected. The 'constructive' elements of negotiation - good preparation, information exchange and solution finding - are all positively related but it is not clear that these three activities are the 'drivers' or indeed are at the core of a negotiation. What does seem to be at the core are preparation and concession management. This reinforces the current understanding that negotiators have a win-lose perception prior to a negotiation and so then prepare for just that; essentially an 'end game' of negotiation that involves exchanging offers, applying pressure and making concessions. The common practice of developing new proposals away from the negotiation table may have the effect of placing the task of solution seeking within this end game rather be a more exploratory and collaborative phase of a negotiation. When following this essentially competitive script, the more 'integrative' aspects (information exchange, finding new solutions) have to fit within the competitiveness context, rather than be elements of a negotiation script that is more strongly oriented towards value adding collaboration.

As this research is preliminary, the survey did not delve into whether the negotiations followed clear patterns such as the recommendation of Lax and Sebenius' (1986) to first create, then claim value. Clearly defined sequences might be difficult to discern in multi-issue negotiations (a category that most business negotiations fall in to) but it is a further area for additional research. Another aspect of sequencing is the transition between solution seeking and concession management. Negotiators engage in activities to generate new solutions but at some point will come to believe that a particular solution is the best one. Persuasion (Cialdini, 2001; Watkins, 2001) may be necessary to get the other party to agree and a closer examination of this transition would be instructive as would be the language to use when bringing a unilaterally developed proposal back to the negotiating table.

A further area for exploration is the way negotiators perceive their differences. ${ }^{1}$ Value can be created by negotiators identifying where their issue preferences differ (Bazerman \& Neale, 1992; Lax \& Sebenius, 1986; Pruitt, 1983) which gives rise to Sebenius (2001) suggesting that it is a mistake to focus on common ground. The survey data showed that negotiators frequently did focus on their common ground while exchanging information about

\footnotetext{
${ }^{1}$ The authors thank one of the reviewers for provoking further consideration of the nature of differences.
} 
each other but did not focus on their differences as a way of finding solutions. However, they did also resort to trade-offs (Figure 3), a resolution strategy that implies differences in priority of the items being traded. These findings suggested that the negotiators' understanding of what their differences are may be reshaped during and the negotiation. Initially there may be a need to unbundle the differences and interests that brought the parties to the table in the first place. For example, two companies selling similar products but in different markets may recognize scope for creating joint value so they open negotiations. Having confirmed that there is enough common ground to warrant continuing to negotiate the parties then proceed to address the detail of the proposed arrangement. The differences that then emerge are more specific but also more amenable to trade. One party may have a preference for early payment scheduling; the other a preference for higher insurance contingency. It is this opportunity for logrolling over issue preferences that is captured well in experimental settings whereas case studies provide more insights into how differences of interest give rise to negotiation opportunities in the first instance.

The high correlation of the two dimensions of satisfaction suggests that negotiations with a good outcome are deemed to have gone well and/or that if negotiations go relatively well, then the outcome is regarded as satisfactory (consistent with the notion of procedural fairness). The exploratory and long distance nature of this survey meant that we did not ask all the questions that might have provided a more objective measure of quality of outcome - for example, 'what is your realistic expectation of outcome; how close was the final outcome to this expectation?' - but there is an indication that if negotiators pay attention to managing the process well, then the outcome will be regarded as satisfactory. A purely rational perspective on outcome satisfaction implies that all outcomes to negotiations should be regarded as satisfactory. An agreement should not be entered into unless it is better than one's BATNA; given that it is better, then it is 'satisfactory'. As explained by Fisheret al. (1991), if one's BATNA is better than the final offer on the table, then no agreement/walking away can be seen as 'satisfactory'. Related to this, there is likely to be an element of ex-post rationalization of any outcome to make it satisfactory, even if the negotiator is disappointed with it.

However, an important point for any negotiator preparing to enter into a negotiation is the probability that those taking part will not feel they have achieved a satisfactory settlement unless - in achieving it - they have engaged in an 'end-game', a period of 'give and take' (with perhaps more of the latter), that brings the negotiation to a conclusion. If there was little of this, there may be a sense that perhaps they ought to have done somewhat better. 
Negotiation strategies that combine an emphasis on cooperation with a 'take it or leave it' offer would not enhance the other party's outcome satisfaction.

Drawing together our findings on what negotiators do, how negotiations work and how satisfied the negotiators are with their efforts, we suggest the survey data indicate the need for cautious cooperation on the part of business negotiators. We conclude that negotiators recognized the mixed motive nature of negotiations, realizing that they need to cooperate if they are going to reach an agreement at all, yet at the same time competing to achieve an agreement that suits them. We also conclude that they will not strive for the best possible outcome, only for one that meets their needs, recognizing that what they really need is an agreement that is better than what they could achieve by walking away. To get to this point they will expect to have engaged in a series of offers and counter offers, a process that makes it a 'real' negotiation. This all points to a degree of competitiveness in the negotiations; the potential of some gain from achieving agreement will lead to cooperation but it will be cautious, not open. In other words, to be effective, business negotiators would do well to be cautious co-operators.

\section{Conclusion}

In focusing on what negotiators actually do in real business negotiations this study both complements and extends the existing findings from an experimental research setting. It complements by demonstrating the use made by practicing negotiators of well established and well researched negotiation tactics. It extends by providing insights into how practicing negotiators manage the challenge of the business context. Negotiators appear to take a more competitive rather than creative path to reach a satisfactory outcome. What the survey data also show is that perhaps these agreements are not quite as satisfactory as they might be and that there is scope for better paths to be found. However, the data also clearly shows that there is not going to be one ideal path - negotiation is interactive and pragmatic, not ideal.

Recognizing this, the paper suggests a number of practical ways that negotiators, particularly those operating in a business context, can - in a cooperative but cautious way - approach their negotiations. They should ensure adequate provision is made for the negotiation component of any business activity to guard against the negotiations themselves being contaminated (for example by a less than benign context that is giving cause for the negotiation). They should adopt a pragmatic approach to negotiation that might unfold rather than be 'wedded' to one particular model, no matter how attractive that model might seem in the training environment. 
This pragmatic approach will include recognizing that negotiations may move from task to task and back again in a seemingly unstructured way. The key point for a negotiator seeking to manage the negotiation is that they need to focus on a task as fully as possible at the time, to help bring a sense of order to the process. Negotiating in this way will also include being prepared for an interactive mix of 'competitive' and 'cooperative' actions by negotiators (on both sides), without trying to tightly manage the process to a predetermined cooperative sequence.

Collecting data through surveys has its limitations but the use of practitioner data has identified aspects of negotiation that warrant further study. One is how, having recognized a need or opportunity for a negotiation to occur, do the parties then develop an understanding of their differences out of which they can then build the detail of an agreement. There would appear to be scope to draw lessons from the area of international relations, particularly with regard to negotiations over mergers or joint ventures. Another avenue of research would be to examine, under more controlled conditions how proposals developed away from the negotiation table can best be presented when the parties resume a joint session.

The business context puts negotiators under a range of commercial, organizational and personal pressures. Culture is a constantly changing factor which is increasingly difficult to isolate in a globalized workplace as negotiating teams are now often comprised of individuals with culturally diverse backgrounds. Revealing more about these diverse pressures that business negotiators experience and the different measures of success that they use will lead to a better understanding of why negotiators make the decisions they do, and provide insights into their understanding of their negotiating power. Exploring the extent to which multi-issue business negotiations follow clearly defined sequences, or perhaps cycles within an overall sequence, will enrich our understanding of the dynamics of the way negotiations are managed in the business context. Further analysis is required to examine dominant sequences of actions by negotiators that may provide an insight into their effectiveness and also enable a closer comparison with the findings of the experimental research. This could extend to the causes and consequences of deadlocks. As one of the survey respondents recounted about a finance negotiation, "We discussed the terms and conditions over the course of three meetings and they came back to us with a final draft but it was still not agreeable to us". Very little in business seems to happen without negotiation and much of it seems to be competitive. Continued research will inform and assist practitioners to be less cautious about adopting a cooperative approach. 


\section{References}

Agndal, H. (2007). Current trends in business negotiation research. Stockholm School of Economics Research Paper, 003.

Axelrod, R. (1990). The evolution of co-operation, Harmondsworth: Penguin.

Baruch, Y., \& Holton, B. C. (2008). Survey response rate levels and trends in organizational research. Human Relations, 81, 1139-1160. doi: 10.1177/0018726708094863

Bazerman, M.H. \& Neale, M.A. (1992). Negotiating rationally. New York, NY: Free Press.

Brett, J. M., Shapiro, D. L., \& Lyte, A. L. (1998). Breaking the bonds of reciprocity in negotiations. Academy of Management Journal, 42, 410-424. doi: 10.2307/257081

Brett, J. (2014). Negotiating globally. $3^{\text {rd }}$ Edition, San Francisco, CA: Jossey-Bass.

Buelens, M., Van De Woestyne, M., Mestdagh, S.. \& Bouckenooghe, D. (2008).

Methodological issues on negotiation research: A state-of-the-art-review. Group Decision and Negotiation, 17, 321-45. doi: 10.1007/s10726-007-9097-3

Butler, J. (1999). Trust, expectations, information sharing, climate of trust and negotiation effectiveness and efficiency. Group and Organization Management, 24, 217-238. doi: $10.1177 / 1059601199242005$

Carnevale, P.J., \& De Dreu, C.K.W. (2004). Methods of negotiation research: Introduction. International Negotiation, 9, 341-344. doi: 10.1163/1571806053498715

Cialdini, R. B. (2001). Harnessing the science of persuasion. Harvard Business Review, 79(9), 72-79. doi:

De Dreu, C.K.W., Beersma, B., Stroebe, K., \& Euwema, M. C. (2006). Motivated information processing, strategic choice and the quality of negotiated agreement. Journal of Personality and Social Psychology, 90, 927-943. doi: 10.1037/0022-3514.90.6.927

De Dreu, C.K.W., Giebels, E. \& Van de Vliert, E. (1998). Social motives and trust in integrative negotiation: the disruptive effects of punitive capability. Journal of Applied Psychology, 83, 408-22. doi: 10.1037/0021-9010.83.3.408

De Dreu, C.K.W., Weingart, L.R. \& Kwon, S. (2000). Influence of social motives on integrative negotiation: a meta-analytic review and test of two theories. Journal of Personality and Social Psychology, 78, 889-905. doi: 10.1037/0022-3514.78.5.889

Deutsch, M. (1973). The Resolution of conflict. New Haven, CT: Yale University Press.

Douglas, A. (1957). The peaceful settlement of industrial and intergroup disputes. Journal of Conflict Resolution, 1, 69-81. doi: 10.1177/002200275700100107

Douglas, A. (1962). Industrial peacemaking. New York: Columbia University Press. 
Druckman, D. (2005). Doing research: Methods of inquiry for conflict analysis. CA: Sage Publications.

Druckman, D. (2009). Intuition or counterintuition? The science behind the art of negotiation. Negotiation Journal, 25, 431-448. doi: 10.1111/j.1571-9979.2009.00237.x

Fells, R. (2000). Labour-management negotiation. Some insights into strategy and language. Relations Industrielles/Industrial Relations, 55, 583-605. doi: 10.7202/051350ar

Fells, R. (2012). Effective negotiation - From research to results. Melbourne: Cambridge University Press.

Fells, R. (2013). Negotiation success - An application of the Halpert et al. model. Negotiation and Conflict Management Research, 6, 133-150. doi: 10.1111/ncmr.12008

Field, A. (2005). Discovering statistics using SPSS, $2^{\text {nd }}$ Edition, London: Sage.

Fisher, R., \& Ertel, D. (1995). Getting ready to negotiate. New York: Penguin Business.

Fisher, R., \& Ury, W. (1981). Getting to yes. London: Hutchinson.

Fisher, R., Ury, W., \& Patton, B. (1991). Getting to yes. New York, NY: Penguin.

Goering, E. (1997). Integration versus distribution in contract negotiations: An interaction analysis of strategy use. Journal of Business Communication, 34 , 383-400. doi: $10.1177 / 002194369703400404$

Ghauri, P., \& Grønhaug, K. (2010). Research methods in business studies. $4^{\text {th }}$ Edition . London: FT Pearson.

Ghauri, P., \& Usunier, J. C. (2003). International business negotiations. Oxford: Pergamon. Graham, J. L. (1986). The problem-solving approach to negotiations in industrial marketing. Journal of Business Research, 14, 546-566. doi: 10.1016/0148-2963(86)90014-7

Halpert, J. A., Stuhlmacher, A. F., Crenshaw, J. L., Litcher, C. D., \& Bortel, R. (2010). Paths to negotiation success. Negotiation and Conflict Management Research, 3, 91-116. doi: 10.1111/j.1750-4716.2010.00051.x

Hames, D. S. (2012). Negotiation. Thousand Oaks, CA: Sage Publications.

Harvey, M. G., \& Griffith, D. A. (2002). Developing effective intercultural relationships: The importance of communication strategies. Thunderbird International Business Review, 44, 455-76. doi: 10.1002/tie.10029

Hendon, D. W., Hendon, R. A., \& Herbig, P. (1996). Cross-cultural business negotiations. Westport, CT.: Praeger.

Hofstede, G. (1994). The business of international business is culture. International Business Review, 3, 1-14. doi: 10.1016/0969-5931(94)90011-6 
Holmes, M. E. (1992). Phase structures in negotiation. In L. L. Putnam \& M. E. Roloff (eds.). Communication and negotiation (pp.83-105). Newbury Park, CA.: Sage.

Kumar, R., \& Worm, V. (2004). Institutional dynamics and the negotiation process: Comparing India and China. International Journal of Conflict Management, 15, 304334. doi: 10.1108/eb022916

Kwon, S., \& Weingart, L. (2004). Unilateral concessions from the other party: concession behavior, attributions, and negotiation judgments. Journal of Applied Psychology, 89, 263-278. doi: 10.1037/0021-9010.89.2.263

Lax, D. A., \& Sebenius, J. K. (1986). The manager as a negotiator. New York, NY: Free Press.

Lempereur, A. \& Colson, A. (2010). The first move. Chichester: John Wiley \& Sons.

Lewicki, R. J., Minton, J. W. \& Saunders, D. M. (2010). Negotiation. New York, NY: McGraw-Hill.

Loewenstein, G., \& Moore, D. A. (2004). When ignorance is bliss: Information exchange an inefficiency in bargaining. Journal of Legal Studies, 33, 37-58. doi: 10.1086/382581

Maynard, D.W. (2010). Demur, defer and deter: Concrete, actual practices for negotiation interaction. Negotiation Journal, 26, 125-43. doi: 10.1111/j.1571-9979.2010.00261.x

McGinn, K. L., \& Keros, A. T. (2002). Improvisation and the logic of exchange in socially embedded transactions. Administrative Science Quarterly, 47, 422-473. doi: $10.2307 / 3094847$

Michaelidou, N., \& Dibb, S. (2006). Using email questionnaires for research: Good practice in tackling non-response. Journal of Targeting Measurement and Analysis for Marketing, 14, 289-296. doi: 10.1057/palgrave.jt.5740189

Miles, M., \& Huberman A. (1994). Qualitative data analysis: an expanded sourcebook, $2^{\text {nd }}$ Edition. Thousand Oaks, CA: Sage Publications.

Movius. H., \& Susskind, L. (2009). Built to win. Boston, MA.: Harvard Business Press.

Olekalns, M., Brett, J. M., \& Weingart, L. R. (2003). Phases, transitions and interruptions: Modeling processes in multi-party negotiations. International Journal of Conflict Management, 14, 191-211. doi: 10.1108/eb022898

Olekalns, M., \& Smith, P.L. (2003). Testing the relationships among negotiators' motivational orientations, strategy choices, and outcomes. Journal of Experimental Social Psychology, 39, 101-117. doi: 10.1016/S0022-1031(02)00520-6 
Peterson, R. M., \& Lucas, G. H. (2001). Expanding the antecedent component of the traditional business model: pre-negotiation literature reviews and planning-preparation propositions. Journal of Marketing Theory \& Practice, 4, 37-49.

Pruitt, D. G. (1983). Achieving integrative agreements. In M. H. Bazerman \& R. J. Lewicki (Eds.), Negotiation in Organizations. (pp.35-50). Beverly Hills, CA: Sage Publications.

Putnam, L. L. (2003). Dialectical tensions and rhetorical tropes in negotiations. Organization Studies, 25, 35-53. doi: 10.1177/0170840604038179

Putnam, L. L. (2005). Discourse analysis: Mucking around with negotiation data. International Negotiation, 10, 17-32. doi: 10.1163/1571806054741083

Putnam, L. L. (2010). Communication as changing the negotiation game. Journal of Applied Communication Research, 38, 325-35. doi: 10.1080/00909882.2010.513999

Putnam, L. L., \& Fuller, R. P. (2014). Turning points and negotiation: The case of the 20072008 Writers' Strike, Negotiation and Conflict Management Research, 7 , 188-212. doi: $10.1111 / \mathrm{ncmr} .12032$

Putnam, L. L., \& Wilson, S. R. (1989). Argumentation and bargaining strategies as discriminators of integrative outcomes. In M. A. Rahim (Ed.). Managing conflict. An interdisciplinary approach (pp.121-41). New York, NY: Praeger.

Rackman, N., \& Carlisle, J. (1978). The effective negotiator part 2: Planning for negotiations. Journal of European Industrial Training, 22-5. doi: 10.1108/eb002302

Raiffa, H. (1982). The art and science of negotiation. Cambridge, MA: Harvard University Press.

Ramsey, J. (2004). Serendipity and the realpolitik of negotiations in supply chains. Supply Chain Management, 9 , 219-29. doi: 10.1108/13598540410544917

Rogers, H., Hossinger, M., Perks, H. \& Ghauri, P. (2010). Effective conduct in International business contractual negotiations. Conference on International and Intercultural Negotiations, Copenhagen Business School, Denmark.

Roloff, M. J., \& Jordon, J. M. (1991). The influence of effort, experience, and persistence on the elements of bargaining plans. Communication Research, 18, 306-332. doi: $10.1177 / 009365091018003002$

Rubin, J. Z., \& Brown, B. R. (1975). The social psychology of bargaining and negotiation. New York, NY: Academic Press.

Rubin, J. Z., Pruitt, D. G. \& Kim, S. H. (1994). Social conflict: Escalation, stalemate and settlement. $2^{\text {nd }}$ Edition. New York, NY: McGraw-Hill. 
Salacuse, J.W. (2003). The global negotiator. New York, NY: Palgrave Macmillan.

Saunders, M., Lewis, P. \& Thornhill, A. (2007). Research methods for business students. $4^{\text {th }}$ Edition. Harlow: Pearson Education Limited.

Schelling, T. C. (1960). The strategy of conflict. Cambridge, MA: Harvard University Press.

Schuster, C. \& Copeland, M. (1996). Global business. New York, NY: Dryden Press.

Sebenius, J. K. (2001). Six habits of merely effective negotiators. Harvard Business Review, 79 (4), 87-95.

Sebenius, J.K. (2009). Negotiation analysis: From games to inferences to decisions to deals. Negotiation Journal, 24, 449-65. doi: 10.1111/j.1571-9979.2009.00238.x

Sinaceur, M. \& Neale, M. A. (2005). Not all threats are created equal: How implicitness and timing affect the effectiveness of threats in negotiations. Group Decision and Negotiation, 14, 63-85. doi: 10.1007/s10726-005-3876-5

Stevens, C. (1963). Strategy and collective bargaining. New York, NY: McGraw-Hill.

Stuhlmacher, A. F., \& Champagne, M. V. (2000). 'The impact of time pressure and information on negotiation processes and decisions'. Group Decision and Negotiation, 9, 471-491.

Susskind, L. (2014). Good for you. Great for me. New York, NY: Public Affairs.

Thompson, L. (2012). The mind and heart of the negotiator, $5^{\text {th }}$ edition, Boston, MA: Pearson.

Thompson, L. (1991). Information exchange in negotiation. Journal of Experimental Social Psychology, 27, 161-79. doi: 10.1016/0022-1031(91)90020-7

Thompson, L. \& Leonardelli, G. (2004). The big bang: the evolution of negotiation research. Academy of Management Executive. 18, 113-117. doi: 10.5465/AME.2004.14776179

Ury, W. (1991). Getting past no: Negotiating with difficult people. New York: Bantam books.

Watkins, M. (2001). Principles of persuasion. Negotiation Journal, 17, 115-37. doi: 10.1023/A: 1013276008562

Watkins, M. (2002). Breakthrough business negotiation. San Francisco, CA: Jossey-Bass.

Watkins, M. (2006). Shaping the Game. Boston, MA: Harvard Business School Press.

Walton, R. E., \& McKersie, R. B. (1965). A behavioral theory of labor negotiation. New York, NY: McGraw-Hill.

Weingart, L. R., Thompson, L. L., Bazerman, M. H. \& Carroll, J. S. (1990). Tactical behavior and negotiation outcomes. International Journal of Conflict Management, 1, 7-31. doi: $10.1108 / \mathrm{eb} 022670$

Weingart, L.R., \& Olekalns, M. (2004). Communication processes in negotiation. In M. J. Gelfand \& J. M. Brett, J.M. (Eds.), The handbook of negotiation and culture (pp.14357). Stanford, CA: Stanford Business Books. 
Weiss, S. E. (2011). Negotiating the Renault-Nissan alliance: Insights from Renault's experience. In Benoliel, M. (Ed.). Negotiation Excellence (pp.315-40). Singapore: World Scientific.

Wheeler, M (2013). The art of negotiation: how to improvise agreement in a chaotic world. New York, NY: Simon \& Schuster.

Zartman, I. W. \& Berman, M. R. (1983). The practical negotiator. New Haven, CT: Yale University Press.

Zartman, I.W. (1988). Common elements in the analysis of negotiation. Negotiation Journal, 4 , 31-43. doi: 10.1111/j.1571-9979.1988.tb00444.x

$\mathrm{Zu}$, Y. (2012). Negotiating supplier deals and supplier relationship management in a Chinese context. Unpublished Masters dissertation, Friedrich Alexander University of ErlangenNuremberg, Germany. 
Figure 1 A model for business negotiations (based on Fells, 2012)

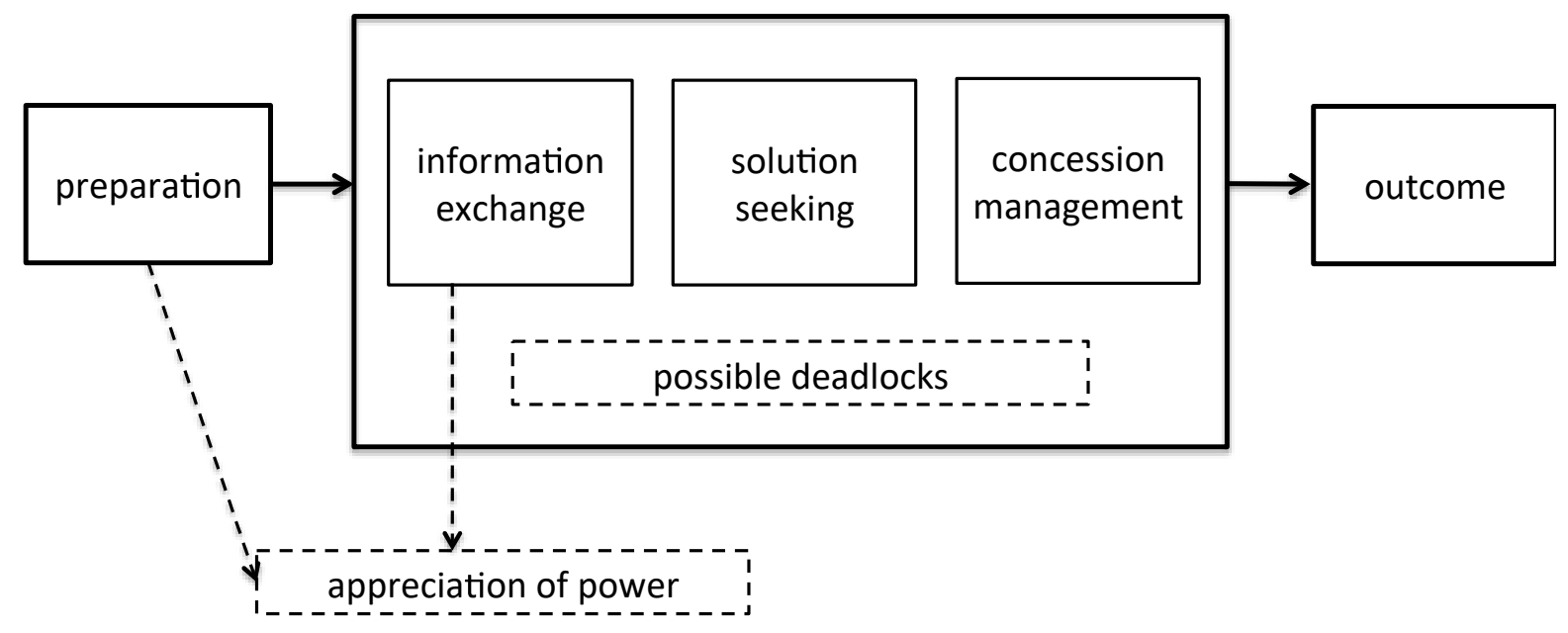


Figure 2 Task model of negotiation with task-related hypotheses

H3 -

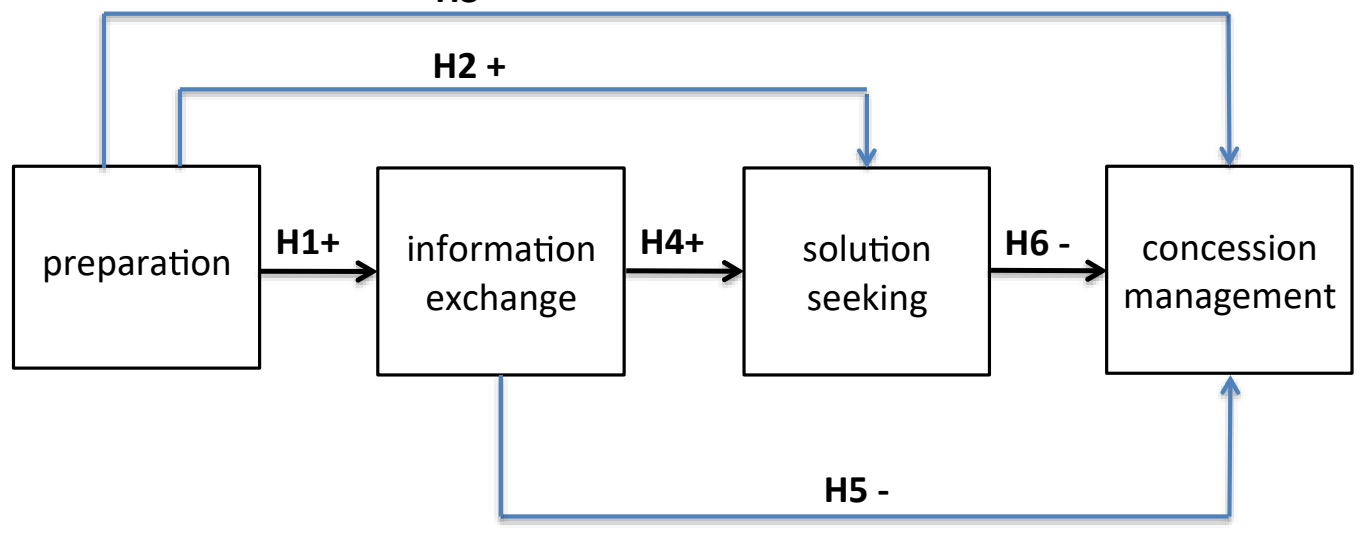


Table 1 Information exchange questions from survey

\begin{tabular}{|l|l|}
\hline & Information exchange \\
\hline 1 & The other party fully explained what they wanted and why they wanted it \\
3 & I asked specific questions and got reasonably clear answers \\
& $\begin{array}{l}\text { I offered some insight into what was important to us to encourage the other } \\
\text { party to likewise }\end{array}$ \\
4 & I drew inferences from what they said and did (or did not say) \\
6 & By focusing on our differences \\
7 & By focusing on common ground \\
\hline
\end{tabular}


Figure 3 What do negotiators do? Information exchange \& seeking solutions
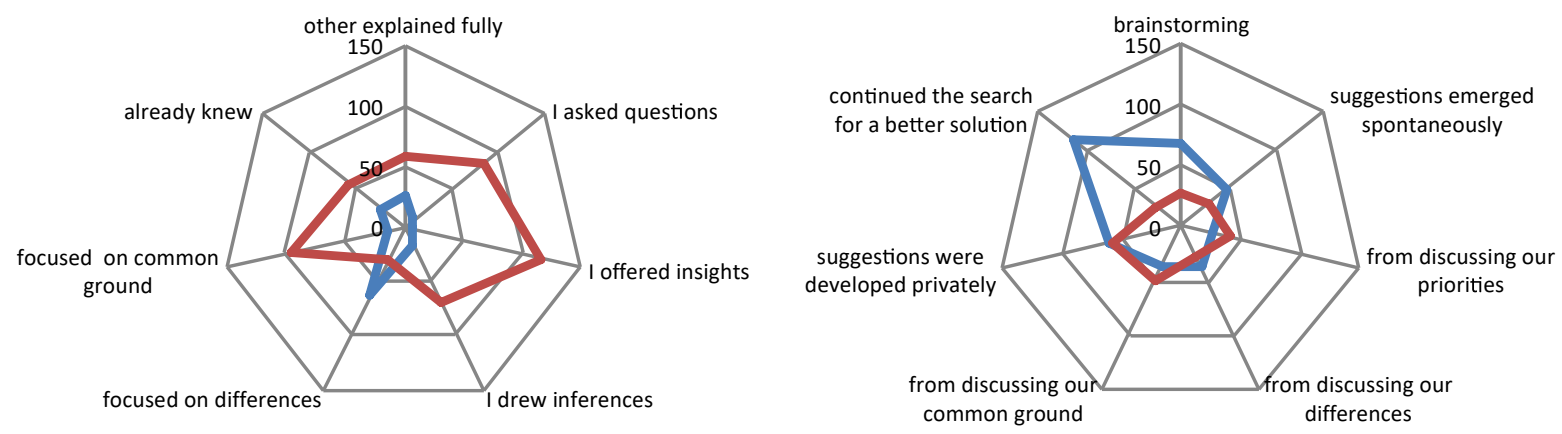

not at all

a great deal 